\title{
WATER QUALITY PARAMETERS OF SIX SELECTED OXBOW LAKES (BAORS) IN BANGLADESH
}

\author{
Gawsia W. ChOWdHurr*, Mosammat Sharmin Bulbul ${ }^{1}$ \\ AND BHAKTA SUPRATIM SARKER ${ }^{1}$ \\ Department of Zoology, University of Dhaka, Dhaka 1000, Bangladesh
}

Key words: Oxbow lake, Physico-chemical parameters, Water quality

In Bangladesh, naturally formed oxbow lakes, locally known as Baors are situated in the south-western part of the country. The increasing demand for water and the wide variety of water uses have impaired many water bodies including the Baors ${ }^{(1)}$. Lakes in Bangladesh face many threats and this is in part due to the dearth of knowledge on the status of lakes as well as the lack of awareness, resource management and appropriate monitoring(1). Physico-chemical parameters are one of the important water quality monitoring tools as any change of these parameters may affect the survival of living organisms ${ }^{(1,2)}$. This study was conducted to observe some physico-chemical parameters in six selected natural oxbow lakes - Baors for proper management of the Baors.

The investigation was carried out during June, 2009 - March, 2010 in 6 oxbow lakes, named as the Bergobindopur Baor (upazila: Chowgacha; district: Jessore), Kathgora Baor (Upazila: Moheshpur; district: Jhenaidah), Fatehpur Baor (upazila: Moheshpur; district: Jhenaidah), Joydia Baor (upazila: Kotchandpur; district: Jhenaidah), Baluhar Baor (Upazila: Kotchandpur; district: Jhenaidah), Marjad Baor (upazila: Chowgacha and Kaliganj; district: Jessore and Jhenaidah) from south-western part of Bangladesh.

Based on reconnaissance visits, 20 sites were selected for sampling from each selected lake, sites separated $200-800 \mathrm{~m}$. Samplings of water were carried out twice between June 2009 and March 2010, covering the rainy monsoon season (June - October, 2009) and the cool dry winter season (November 2009 - March, 2010). Hence, 240 water samples were analysed (6 lakes $\times 20$ samples $\times 2$ seasons).

Water quality indicating physico-chemical parameters such as transparency, temperature, conductivity, $\mathrm{pH}$, dissolved oxygen (DO), calcium (Ca) hardness, chlorophyll- $a(\operatorname{chl} a)$, total nitrogen (TN) and total phosphorus (TP) of water were studied using the standard methods ${ }^{(3)}$. Water temperature was measured once with a digital thermometer. A fluorometer (Aquafluor Handheld Fluorometer, Turner Designs,

*Author for correspondence: <gawsia@gmail.com>. ${ }^{1}$ Noakhali Science and Technology University, Shonapur, Noakhali 3802, Bangladesh 
Sunnyvale, CA, USA) was used for $\geq 3$ measurements of chl- $a$ concentration/site. Concentration of dissolved oxygen (DO), $\mathrm{pH}$, and conductivity were measured using hand-held DO ( $\mathrm{DO}_{2}$ Meter 9200; Jenway, Stone, UK), pH (eco Testr pH2, Vernon Hills, IL, USA) and conductivity (EC Testr 11+ Eutech instrument) meters. From each site, Secchi depth, TP (HACH Lange Test Kit; HACH Corporation, Loveland, Colorado), TN (HACH Lange Test Kit), and $\mathrm{Ca}(\mathrm{HACH}$ Lange Test Kit) were recorded(3).

During the study period the lowest and highest mean value of transparency were recorded as $8.28 \pm 0.34$ and $22.70 \pm 0.58$ from Fatehpur Baor and Marjad Baor, respectively (Table 1). As the $\mathrm{p}$ value was $<0.05$ at the significance level $\alpha=0.05$, there was significant difference of means of the transparency value in the six Baors. Transparency of water varies with different factors such as silt, microscopic organisms, suspended organic matter, seasons of the year, latitude and intensity of light, application of manure, grazing pressure of fishes or shellfishes and rainfall( ${ }^{(4,5)}$.

Temperature is an important parameter in limnological studies, since it affects the distribution of organisms, density of water and solubility of gases and minerals ${ }^{(4)}$. Variation of temperature $\left({ }^{\circ} \mathrm{C}\right)$ of Baors ranged from $18-34^{\circ} \mathrm{C}$ with the mean value $27.52 \pm$ 0.29 . There was no significant difference $(p>0.05)$ of means of temperature of the Baors. Water temperature is the environmental physical parameter which affects most of the organisms $s^{(6,7)}$. Generally $20-30^{\circ} \mathrm{C}$ is the temperature requirement for warm water fishes and for prawn culture the suitable temperature range is $21.9-33.5^{\circ} \mathrm{C}(7,8)$. Therefore, the temperature recorded from the six Baors was suitable for aquatic life forms.

The maximum mean value of conductivity $(\mu \mathrm{S} / \mathrm{cm})$ was recorded as $626.67 \pm 40.77$ from Fatehpur Baor and minimum mean value was recorded as $129.52 \pm 15.64$ from Kathgara Baor (Table 1). Significant difference $(p<0.05)$ exists in the measured conductivity of the Baors. According to Lawson (1997) distilled water has a conductivity of about $1 \mu \mathrm{S} / \mathrm{cm}$ while natural freshwaters have conductivities ranging from $20-1,500$ $\mu \mathrm{S} / \mathrm{cm}^{(6)}$. Therefore, the observed conductivity of the six Baors was within expected range.

The value of $\mathrm{pH}$ ranged from 6.89 - 10.9 with the highest mean value $9.30 \pm 0.13$ recorded from Fatehpur Baor and lowest mean value $7.62 \pm 0.07$ recorded from Marjad Baor (Table 1). The mean value of $\mathrm{pH} 8.29 \pm 0.04$ recorded in the present study showed that the water of the six baors was alkaline in nature. Kabir and Naser (2011) made similar observations from the Chandbill oxbow lake (2). According to Trivedi and Raj (1992), the optimum $\mathrm{pH}$ range for aquatic life varied from 6.8 to $9.0^{(8)}$. In this study, Ca hardness (mg/l) ranged from $47-322 \mathrm{mg} / \mathrm{l}$ in two seasons. The minimum mean value $78.25 \pm 3.32$ was recorded from Marjad Baor while maximum mean value $228.98 \pm 9.69$ was recorded from Fatehpur Baor (Table 1). High significant difference $(\mathrm{p}<0.05)$ of the means of Ca hardness measurements of the Baors was evident. 


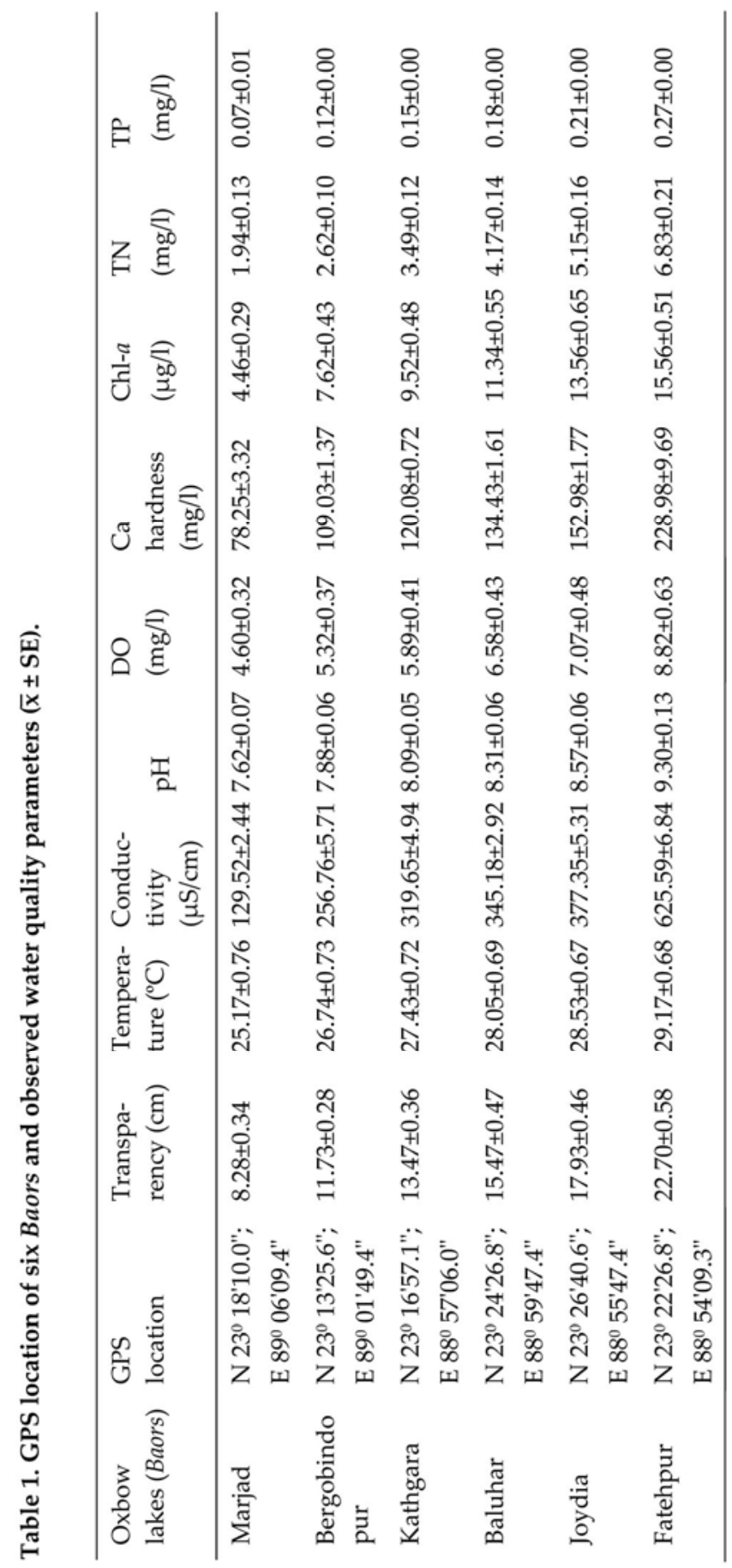


Dissolved oxygen content was found to fluctuate from $6-18 \mathrm{mg} / \mathrm{l}$ with a minimum mean value $4.60 \pm 0.32$ recorded from Marjad Baor and maximum mean value $8.82 \pm 0.63$ from Fatehpur Baor (Table 1). This observation has similarity with the findings of Kabir and Naser (2011)(2). There is no significant difference $(p>0.05)$ of means of DO between the Baors. Generally, a minimum DO concentration of $5 \mathrm{mg} / \mathrm{l}$ is recommended for warmwater fish and $6 \mathrm{mg} / \mathrm{l}$ for cold water species ${ }^{(6,7)}$. Also Lawson (1997) mentioned that small differences in the metabolic rate of an aquatic community can cause rapid changes in DO concentrations ${ }^{(6)}$.

Chlorophyll- $a$ is common in all photosynthesizing plants. For this reason, the amount of planktonic (suspended) algae in a lake is estimated by using chlorophyll- $a$ concentration $^{(10)}$. In this study, chlorophyll- $a$ ranged from $2.02-18.45 \mu \mathrm{g} / \mathrm{l}$ with the minimum mean value $4.46 \pm 0.29$ recorded from Marjad Baor and maximum mean value $15.56 \pm 0.51$ Fatehpur Baor (Table 1). Significant difference $(\mathrm{p}<0.05)$ of means of Chl- $a$ of the selected six baors was evident.

The TN content recorded in this study ranged from 2 - $10 \mathrm{mg} / \mathrm{l}$ with the minimum mean value of $1.94 \pm 0.13$ observed in Marjad Baor and maximum value $6.83 \pm 0.21$ observed in Fatehpur Baor (Table 1). There was significant difference $(\mathrm{p}<0.05)$ of means of TN observed in the six Baors. According to water quality parameters and indicators: Fact Sheet 2, the range of TN includes $<0.5 \mathrm{mg} / \mathrm{l}$ (low), $0.5-1 \mathrm{mg} / \mathrm{l}$ (medium), $>1$ - $3 \mathrm{mg} / 1$ (high) and $>3$ (very high)(9). The standard range of nitrate for most of the organisms' survival is $0-3.0 \mathrm{mg} / \mathrm{l}^{(7)}$. The water of the selected six Baors was observed as very high in TN content. From this study the TP (mg/l) ranged from $0.1-0.28 \mathrm{mg} / \mathrm{l}$ with the minimum mean value of $0.07 \pm 0.01$ recorded from Marjad Baor and maximum mean value $0.27 \pm$ 0.00 recorded from Fatehpur Baor (Table 1). Significant difference $(\mathrm{p}<0.05)$ of mean values of TP contents reported from the six Baors was observed. TP concentrations above $0.030 \mathrm{mg} / \mathrm{l}$ are enough to stimulate nuisance algae growth water quality standard for lakes is $0.050 \mathrm{mg} / \mathrm{l} \mathrm{TP}(9,10)$.

An understanding on water quality parameters becomes increasingly important for lake management. Therefore, this study can be used as a baseline study for further research and actions for effective Baor management.

\section{References}

1. Chowdhury GW, B Gallardo, and DC Aldridge 2015. Development and testing a biotic index to assess the ecological quality of lakes in Bangladesh. Hydrobiologia (doi:10.1007/s10750015-2399-6). pp. 1-15.

2. Kabir AKMN and MN Naser 2011. Physico-chemical aspects of Chandbill Oxbow Lake of Meherpur, Bangladesh. Dhaka Univ. J. Biol. Sci. 20(1): 31-39.

3. APHA 1989. Standard Methods for the Examination of Water and Wastewater, 17th edn. American Public Health Association, Washington, DC. pp. 540. 
4. Boyd CE 1990. Water quality in ponds for aquaculture. Birmingham Publishing Co., Birmingham. Alabama, USA. pp. 482.

5. Almazan G. and CE Boyd 1978. An evaluation of secchi disk visibility for estimating plankton density in fish ponds. Hydrobiologia 65: 601-608.

6. Lawson TB 1997. Fundamentals of Aquaculture Engineering. CBS Publications and Distributors, India. pp. 355.

7. Pillay TVR and MN Kutty 2005. Aquaculture: principles and practices (2nd edn.). WileyBlackwell. Technology and Engineering, USA. pp. 624.

8. Trivedi PR and G Raj 1992. Environmental water and soil analysis. Akshdeep Publ. House, New Delhi, India. pp. 72.

9. Hudson H 1998. Lake Notes: Common lake water quality parameters. The Northeastern Illinois Planning Commission. Chicago. Illinois. http://www.epa.state.il.us/water/conservation/ lake-notes/quality-parameters.pdf [accessed on 6 October 2010].

10. Water Quality Parameters: A Fact Sheet of the Pennsylvania Lake Management Society (PALMS). http://palakes.org/publications/wq_parameters.pdf. [Accessed on 6 October 2010].

(Manuscript received on 4 October, 2015; revised on 13 January, 2016) 